\title{
Revisit of the Cardiac Inward Rectifier Potassium Current $\mathbf{I}_{\mathbf{K} 1}$
}

\author{
Gui-Rong Li*,1 and Ming-Qing Dong ${ }^{2}$
}

\begin{abstract}
${ }^{I}$ Departments of Physiology and Medicine, Li Ka Shing Faculty of Medicine, the University of Hong Kong, Pokfulam, Hong Kong SAR China; ${ }^{2}$ Deparment of Pathology and Pathophysiology, Fourth Military Medical University, Xi'an, China
\end{abstract}

\begin{abstract}
Inward rectifier potassium currents are present in different types of cells. In the heart, the inward rectifier potassium current $\mathrm{I}_{\mathrm{K} 1}$ plays a crucial role in maintaining cardiac resting membrane potential and excitability. It is generally believed that the strong inward rectification of cardiac $\mathrm{I}_{\mathrm{K} 1}$ channels makes it conduct substantial current near the resting potential but carry little or no current at depolarized potentials. However, recent studies in native cardiac myocytes and HEK 293 cell line stably expressing human Kir2.1 gene have demonstrated that a significant transient outward current carried by $\mathrm{I}_{\mathrm{K} 1}$ channels is activated by the upstroke of action potential. This review will revisit cardiac $\mathrm{I}_{\mathrm{K} 1}$ channels, especially the previously-ignored transient outward component of $\mathrm{I}_{\mathrm{K} 1}$ carried by Kir2.1 channels.
\end{abstract}

Keywords: Inward rectifier potassium channels, cardiac inward rectifier potassium current, $\mathrm{I}_{\mathrm{K} 1}, \mathrm{Mg}^{2+}$, polyamines .

\section{INTRODUCTION}

The term "inward rectification" was originally used by Bernard Katz in 1949 to describe a novel current that rectifies "anomalously" in the inward direction, compared with the outward rectifier current in skeletal muscle [1], and by Silvio Weidmann in 1955 to describe the current recorded in sheep cardiac Purkinje fibers with a two-electrode voltage-clamp technique [2]. The strong inward rectifier $\mathrm{K}^{+}$ current was also recorded in ventricular trabeculae and papillary muscles [3,4] and atrial fibers [5] of frog heart using a sucrose-gap voltage clamp technique, and the current is so strong that only small currents can be measured in the outward direction at voltages positive to the $\mathrm{K}^{+}$reversal potential $\left(\mathrm{E}_{\mathrm{K}}\right)$ while large inward currents can be easily observed negative to it. This cardiac inward rectifier $\mathrm{K}^{+}$ current is referred as $I_{K 1}$ and is recognized to play an important role in stabilizing membrane potential in the heart $[6,7]$.

$\mathrm{I}_{\mathrm{K} 1}$ has been extensively studied in mammalian artery and cardiac myocytes from different species including human [817] using patch voltage-clamp technology [18, 19]. Molecular identities, mechanisms of inward rectification, and signaling regulation of $\mathrm{I}_{\mathrm{K} 1}$ were well investigated in last decade. Recent studies demonstrated that upregulation or downregulation of $\mathrm{I}_{\mathrm{K} 1}$ may induce short or long QT syndrome. This review will revisit cardiac $\mathrm{I}_{\mathrm{K} 1}$ to summarize unsolved mysteries of $\mathrm{I}_{\mathrm{K} 1}$ channels and the previouslyignored transient outward component of $\mathrm{I}_{\mathrm{K} 1}$ channels elicited by the upstroke of cardiac action potential. Excellent review articles [20-22] are recommended to readers for the rich literature on inward-rectifier $\mathrm{K}^{+}$channels.

*Address correspondence to this author at the L4-59, Laboratory Block, FBM, Li Ka Shing Faculty of Medicine, The University of Hong Kong, 21 Sassoon Road, Pokfulam, Hong Kong SAR China; Tel: 852-2819-9513; Fax: 852-2855-9730; E-mail: grli@hkucc.hku.hk

\section{MOLECULAR IDENTITIES OF $I_{K 1}$ AND HETERO- GENEITY IN THE HEART}

Molecular identities of different ion channels including inward rectifier $\mathrm{K}^{+}$channels have been clarified with the development of molecular cloning technology [23-28]. It has been recognized that the inward rectifier $\mathrm{K}^{+}$channels Kir2.x (Kir2.1, Kir2.2 and Kir2.3) mediate cardiac $\mathrm{I}_{\mathrm{K} 1}[20,29]$. Kir2.x channels, similar to Kv channels, are tetramers [30]. However, Kir subunits contain two transmembrane domains (M1 and M2), instead of six transmembrane domains (S1S6) in $\mathrm{Kv}$ channels. Kir subunit has cytoplasmic aminoterminal and carboxyl-terminal and a pore loop structure (P region) between $\mathrm{M} 1$ and $\mathrm{M} 2$. Like other $\mathrm{K}^{+}$channels, the common sequence Gly-Tyr-Gly (GYG ) of Kir2. $\mathrm{x}$ in the P loop determines $\mathrm{K}^{+}$-selectivity $[20,29,31]$. The assembly of Kir2.x subunits into homomeric or heteromeric channels has been considered to be related to heterogeneous $\mathrm{I}_{\mathrm{K} 1}$ distribution in cardiac myocytes [32-34].

Therefore, the molecular compositions of cardiac $\mathrm{I}_{\mathrm{K} 1}$ channels are homomeric or heteromeric tetramers composed of different Kir2 isoforms with various proportions in different species of cardiac myocytes [8, 34-37]. Thus, species and regional heterogeneities of $\mathrm{I}_{\mathrm{K} 1}$ are present in mammalian hearts $[33,38-40]$. The properties of $I_{K 1}$ channels in atrial myocytes are different from those in ventricular myocytes, and the density of $\mathrm{I}_{\mathrm{K} 1}$ is generally greater in ventricular myocytes than that in atrial myocytes. Furthermore, $\mathrm{I}_{\mathrm{K} 1}$ channels in ventricular myocytes exhibit a stronger and more complete inward rectification and more prominent negative slope conductance at depolarized potentials than those in atrial myocytes [10, 33, 40-42]. This may account for different morphologies of action potentials in atrial and ventricular myocytes $[38,40]$.

\section{MOLECULAR MECHANISM OF HETEROGENEOUS $I_{K 1}$ CHANNELS IN THE HEART}

$\mathrm{I}_{\mathrm{K} 1}$ channels are heterogeneously present in atrial and ventricular myocytes in different species. Although regional 
dependence of cardiac $\mathrm{I}_{\mathrm{K} 1}$ channels was initially believed to be related to the variation in concentrations of intracellular free polyamines, it has been recognized that the heterogeneity of cardiac $\mathrm{I}_{\mathrm{K} 1}$ channels in the heart is resulted from inhomogeneous expression of different isoforms of Kir2 genes in atrial and ventricular myocytes, since different Kir2 channels exhibit distinct rectification profiles. Kir2.1 channels exhibit a strong inward rectification with a large outward component $[28,38]$. The single channel conductance of Kir2.1 is $35 \mathrm{pS}$. Kir2.3 channel shows a decreased inward rectification with a smaller outward component, and single channel conductance of Kir2.3 channel is $13 \mathrm{pS}[27,38]$.

The heterogeneous $\mathrm{I}_{\mathrm{K} 1}$ expression in the heart has been described in guinea pig [38, 42], rabbit [33], sheep [38], canine [40], and human [43-45]. In the canine heart, Kir2.1 protein level was greater in ventricular myocytes than that in artrial myocytes; while Kir2.3 protein level was greater in atrial than that in ventricular myocytes [40]. Kir2.2 channel could not be detected in the heart of canine, sheep, or guinea pig [38, 40]. Dhamoon and colleagues have recently demonstrated the important evidence that properties of $I_{K 1}$ in native cardiac myocytes are closely related to Kir2.x isoform expression [38]. Kir2.3 channel was predominantly expressed in sheep atria, $\mathrm{I}_{\mathrm{K} 1}$ did not rectify completely. Single channel conductance $(9.9 \mathrm{pS})$ of $\mathrm{I}_{\mathrm{K} 1}$ in sheep atria corresponds to single channel conductance $(13 \mathrm{pS})$ of Kir2.3 channels. In addition, steady-state outward component of Kir2.1 currents, similar to that of $\mathrm{I}_{\mathrm{K} 1}$ in ventricular myocytes, is increased as bath $\mathrm{K}^{+}$is elevated to $10 \mathrm{mM}$, whereas Kir2.3 currents, such as $I_{K 1}$ in sheep atria, are not altered by the elevation of increasing bath $\mathrm{K}^{+}$concentration [38].

On the other hand, guinea pig atrial $\mathrm{I}_{\mathrm{K} 1}$ encoded by Kir2.1 channels rectifies completely [38, 42] and shows an increase in outward currents with elevating $\mathrm{K}^{+}$o (Dhamoon et $a l ., 2004)$. The heterogeneuous expression of $\mathrm{I}_{\mathrm{K} 1}$ in guinea pig heart is believed to be related to various concentrations of polyamines in atrial and ventricular myocytes [46]. Although ventricular myocytes in both sheep and guinea pig express Kir2.1 channels with a certain amount of Kir2.3, outward $\mathrm{I}_{\mathrm{K} 1}$ rectifies completely and increases in high $\mathrm{K}_{\mathrm{o}}^{+}$, which displays Kir2.1-like properties. Therefore, the unique properties of individual Kir2 isoforms as well as heteromeric Kir2.x complexes, and also variable concentrations of free intracellular polyamines determine regional and species differences of $I_{K 1}$ in the heart. However, the possibility that differences in subcellular distribution might contribute to overall variable protein densities of $\mathrm{I}_{\mathrm{K} 1}$ cannot be excluded in explaining the species and regional heterogeneity of cardiac $\mathrm{I}_{\mathrm{K} 1}$ rectification [40].

\section{MECHANISMS UNDERLYING INWARD RECTIFI- CATION OF $I_{K 1}$}

Under symmetrical $\mathrm{K}^{+}$conditions, single channel conductance of cardiac $\mathrm{I}_{\mathrm{K} 1}$ is ohmic and the inward rectification of cardiac $I_{K 1}$ is believed to be attributed to the blockade of the channel pore by intracellular cationic molecules, e.g. $\mathrm{Mg}^{2+}$ [16]. Intracellular free $\mathrm{Mg}^{2+}$ ions $\left(\mathrm{Mg}^{2+}{ }_{\mathrm{i}}\right)$ blocked guinea pig cardiac ventricular $\mathrm{I}_{\mathrm{K} 1}$ in a voltage-dependent manner $[16,47]$. However, the rectification could not be abolished by removing $\mathrm{Mg}^{2+}{ }_{\mathrm{i}}$ and the weak voltage dependence of $\mathrm{Mg}^{2+}{ }_{\mathrm{i}}$ block could not account for the steep rectification observed in the ventricular $\mathrm{I}_{\mathrm{K} 1}[16]$. Therefore, the intrinsic channel gating was proposed to interpret the inward rectification in native cardiac myocytes [48-51].

The studies on molecular mechanism of rectification was facilitated with cloned inward rectifier channels [23, 28]. In cloned Kir2.1 channels heterologously expressed in Xenopus oocytes or mammalian cell lines, the intracellular free polyamines spermine, spermidine, and putrescine were found to block outward currents of Kir2.1 channels with steep voltage dependence, similar to $\mathrm{I}_{\mathrm{K} 1}$ in native cells $[52,53]$, and the effect was stronger than that of $\mathrm{Mg}^{2+}[51,54]$. It is generally accepted that molecular mechanism of inward rectification is related to the pore block of $\mathrm{I}_{\mathrm{K} 1}$ channels by intracellular polyamines and $\mathrm{Mg}^{2+}{ }_{\mathrm{i}}$. In addition, surface charge screening of polyamines and $\mathrm{Mg}^{2+}$ may also play a role [55].

Site-directed mutagenesis studies suggest that the strong inward rectification of Kir2.1 channels is dependent on three negatively charged residues located in the second transmembrane domain (D172) and the carboxyterminal tail (E224 and E299). These amino acid residues are present in all Kir2.x channels, and are critically important for polyamine and $\mathrm{Mg}^{2+}$ binding and voltage-dependent block of the channel pore $[53,54,56,57]$. However, the possibility that other amino acid residues may also be involved in the inward rectification of the channel can not be excluded.

\section{UNSOLVED MYSTERIES FOR THE MOLECULAR MECHANISM OF $I_{K 1}$ RECTIFICATION}

The conclusion that the pore block by intracellular polyamines and/or $\mathrm{Mg}^{2+}{ }_{\mathrm{i}}$ contributes to the inward rectification of $I_{K 1}$ or Kir2.x channels is made based mainly on experiments conducted under conditions of high extracellular $\mathrm{K}^{+}\left(\mathrm{K}_{\mathrm{o}}^{+}\right)$concentrations $[49,52,56,58]$. It is well known that $I_{K 1}$ is a unique current that is highly dependent on $\mathrm{K}^{+}$o concentration. The conductance of $\mathrm{I}_{\mathrm{K} 1}$ channels increases with elevating $\mathrm{K}^{+}$concentration, and decreases with reducing $\mathrm{K}^{+}$o concentration. Moreover, the conductance disappears with removal of $\mathrm{K}_{\mathrm{o}}^{+}[15,42,59,60]$.

The reports for the effect of $\mathrm{Mg}^{2+}{ }_{\mathrm{i}}$ on outward component of cardiac $\mathrm{I}_{\mathrm{K} 1}$ channels or Kir2.1 channels were controversial and dependent on various experimental conditions. $\mathrm{Mg}^{2+}{ }_{\mathrm{i}}$ block of outward component positive to $\mathrm{K}^{+}$equilibrium $\left(\mathrm{E}_{\mathrm{K}}\right)$ in $\mathrm{I}_{\mathrm{K} 1}$ or Kir2.1 channels is usually observed in whole-cell and/or inside-out patch under conditions in which the channel conductance is increased with high $\mathrm{K}^{+}$ concentrations or symmetrical $\mathrm{K}^{+}$conditions $[49,52,56,58]$, but not under conditions where physiological $\mathrm{K}_{0}^{+}$is employed in cardiac myocytes $[50,59,61]$. The increased conductance of $\mathrm{I}_{\mathrm{K} 1}$ or Kir2.1 channels with high $\mathrm{K}^{+}$o concentrations or symmetrical $\mathrm{K}^{+}$is likely related to the alteration of channel conformation, which may be highly sensitive to block by $\mathrm{Mg}^{2+}$. Under physiological $\mathrm{K}^{+}$and temperature conditions, the outward component or its rectification property of $\mathrm{I}_{\mathrm{K} 1}$ channels was not affected in cardiac myocytes from dogs, cats, rabbits, and guinea pigs dialyzed with a $\mathrm{Mg}^{2+}$-free pipette solution [59, 61], or in HEK 293 cells stably expressing human Kir2.1 genes with a $\mathrm{Mg}^{2+}$-enriched (8 $\mathrm{mM}$ free $\mathrm{Mg}^{2+}$ ) pipette solution [60]. 
Therefore, whether free $\mathrm{Mg}^{2+}{ }_{\mathrm{i}}$ contributes to the inward rectification of $\mathrm{I}_{\mathrm{K} 1}$ channels should be re-confirmed under physiological conditions.

On the other hand, the studies with polyamines have greatly improved the understanding of molecular mechanisms of Kir channels rectification [53, 56, 57, 62]. However, almost all the studies with polyamines were performed under conditions of increased $\mathrm{K}^{+}{ }_{\mathrm{o}}$ concentrations $[53,56,57,62]$, in which the channel conformation and sensitivity to polyamines would be altered. Polyamines are intracellular positively charged molecules and play an important role in cell growth, proliferation, apoptosis, and effects that involve DNA, RNA, transcription factors, nuclear protooncogenes, RNA-binding proteins, and cell growth signal transduction cascades [63-65]. In the heart, the polyamine concentrations are over a range of 100 to $500 \mu \mathrm{M}$ $[46,63]$ with a free concentration of 20-30 $\mu \mathrm{M}[46]$.

If physiological micromolar levels of polyamines are required to make the pore block of $\mathrm{I}_{\mathrm{K} 1}$ or Kir2.x channels under physiological $\mathrm{K}_{0}^{+}$, the inward rectification of the current would be attenuated in cells dialyzed with polyamine-free pipette solution in whole-cell patch configuration; however, this has never been observed [42, $44,50,59-61,66]$. Interestingly, we recently found that additional inclusion of $100 \mu \mathrm{M}$ spermine in patch pipette solution inhibited both the transient outward component and steady-state component of human Kir2.1 current without affecting the rectification property and resting membrane potential under physiological $\mathrm{K}_{\mathrm{o}}^{+}$[60]. Therefore, the degree that intracellular polyamines contribute to inward rectification should be re-evaluated under physiological $\mathrm{K}_{\mathrm{o}}^{+}$. In addition, it is important to clarify why intracellular polyamines block the channel in a single direction mode, i.e. inhibiting only outward-going $\mathrm{K}^{+}$without affecting inwardgoing $\mathrm{K}^{+}$ion under physiological concentrations.

\section{TRANSIENT OUTWARD CURRENT CARRIED BY $I_{K 1}$ OR Kir2.x CHANNELS}

The depolarizartion-activated transient outward current carried by $\mathrm{I}_{\mathrm{K} 1}$ channels or Kir2.1 channels [42, 60, 67, 68] were ignored in past decades, because $I_{K 1}$ channels were considered to act as a diode active only during hyperpolarization of the membrane [16, 69], and very little or no current passes through the channel in the outward direction during depolarization under physiological conditions [47, 70]; also $\mathrm{I}_{\mathrm{K} 1}$ channels were believed to be inactivated during the upstroke and plateau phases of the action potential and was consequently available for repolarization only during phase 3 of the cardiac action potential [71, 72].

Actually, the transient outward component of $\mathrm{I}_{\mathrm{K} 1}$ was observed in guinea pig ventricular myocytes under high $\mathrm{K}_{\mathrm{o}}^{+}$ $(14-80 \mathrm{mM})$, but, the $I-V$ relation of the depolarizationinduced instantaneous $\mathrm{I}_{\mathrm{K} 1}$ was linear [48, 73], and the monoexponential inactivation time constant of instantaneous $\mathrm{I}_{\mathrm{K} 1}$ ranges only from 1.1 to $7.7 \mathrm{~ms}[48,49]$, which is believed to be related to inward rectification caused by the blockade of the channel by $\mathrm{Mg}^{2+}{ }_{\mathrm{i}}$ [48] and polyamines [70] and/or intrinsic, voltage-dependent gating or closing of the $\mathrm{I}_{\mathrm{K} 1}$ channel $[16,48,49]$. Because the time constant of the transient outward component recorded under high $\mathrm{K}_{\mathrm{o}}^{+}$ conditions was very small, physiological significance of transient outward current of $\mathrm{I}_{\mathrm{K} 1}$ or Kir2.x channels activated by membrane depolarization was therefore ignored.

In 1998, we recorded a 4-AP-insensitive transient outward current by depolarization voltage steps in a wholecell patch configuration in a $\mathrm{Na}^{+}$-free bath medium containing physiological concentration $(5 \mathrm{mM})$ of $\mathrm{K}^{+}, 5 \mathrm{mM}$ 4-AP (to block the classical transient outward $\mathrm{K}^{+}$current $\mathrm{I}_{\mathrm{to}}$ ) and $200 \mu \mathrm{M} \mathrm{Cd}^{2+}$ (to block $\mathrm{I}_{\text {Ca.L }}$ ) [59]. Voltage and timedependent transient outward current (i.e. peak current or $\mathrm{I}_{\text {peak }}$ ) and classic $\mathrm{I}_{\mathrm{K} 1}$ ('quasi'- steady-state current or $\mathrm{I}_{\mathrm{SS}}$ ) are simultaneously suppressed by removal of $\mathrm{K}^{+}$or addition of the $\mathrm{I}_{\mathrm{K} 1}$ blocker $\mathrm{Ba}^{2+}$ in bath medium. $\mathrm{Ba}^{2+}$ - or $\mathrm{K}^{+}$-sensitive $I-V$ relationship for the peak current of the transient outward component showed a moderate inward rectification (Fig. 1A). The transient outward current exhibited significant voltage-dependent availability (the half-inactivation potential $\mathrm{V}_{1 / 2}:-43.5 \mathrm{mV}$ ) and time-dependent recovery from inactivation (time constant: $13.2 \mathrm{~ms}$ ). The inactivation phase of the significant transient outward current was fitted to biexponential function with inactivation time constants of 8 $\left(\operatorname{tau}_{1}\right)$ and $80\left(\operatorname{tau}_{2}\right) \mathrm{ms}$ at $0 \mathrm{mV}$ [59]. Action potential clamp revealed two components of $\mathrm{Ba}^{2+}$-sensitive currents during the action potential: one transient outward component evident immediately after upstroke of action potential and another component during phase 3 repolarization corresponding to classic $\mathrm{I}_{\mathrm{K} 1}$. Little current was present during the plateau of the action potential (Fig. 1A-C).

We initially thought that the significant transient outward current was an ignored component of $\mathrm{I}_{\mathrm{K} 1}$ activated by depolarization since the $\mathrm{Ba}^{2+}$ application or removal of $\mathrm{K}^{+}{ }_{\mathrm{o}}$ inhibited both classic $\mathrm{I}_{\mathrm{K} 1}$ and the transient outward component. However, this notion was criticized by reviewers during the manuscript submission, because it is against the traditional concept that $\mathrm{I}_{\mathrm{K} 1}$ is a time- and voltageindependent background current. Therefore, the transient outward current with inward rectification was referred as $\mathrm{I}_{\text {to.ir }}$, and discussed it as a "novel" current [59]. The so-called "novel" $\mathrm{Ba}^{2+}$ - or $\mathrm{K}^{+}{ }_{0}$-sensitive $\mathrm{I}_{\text {to.ir }}$ was also found in guinea pig atrial and ventricular myocytes with similar properties [42] (Fig. 1B) to those observed in dog ventricular myocytes [59]. Although the possibility that $\mathrm{Ba}^{2+}$-sensitive transient outward $\mathrm{K}^{+}$current with inward rectification is carried by $\mathrm{I}_{\mathrm{K} 1}$ channels was proposed by Zhabyeyev and colleagues [68], their study was performed in cardiac myocytes dialyzed by a low $\mathrm{K}^{+}$-pipette solution containing $10 \mathrm{mM} \mathrm{K}{ }^{+}$and $130 \mathrm{mM}$ $\mathrm{Cs}^{+}$.

The confirmatory evidence that $\mathrm{I}_{\mathrm{K} 1}$ channels indeed carry the $\mathrm{I}_{\text {to.ir }}$ observed in dog and guinea pig cardiac myocytes $[42,59,68]$ was recently obtained in HEK 293 cells stably expressing human Kir2.1 genes in a whole-cell patch configuration under physiological $\mathrm{K}^{+}$conditions [60]. The cells stably expressing hKir2.1 gene had a transient outward current activated by depolarization voltage, showed a I-V relationship with intermediate inward rectification (Fig. 1C), and exhibited time-dependent inactivation and rapid recovery from inactivation. The half potential $\mathrm{V}_{1 / 2}$ of availability of the current was $-49.4 \mathrm{mV}[60]$, close to that in native ventricular myocytes [42, 59]. Moreover, in HEK 293 cells stably expressing human Kir2.1 gene, action potential waveform clamp revealed two components of outward 

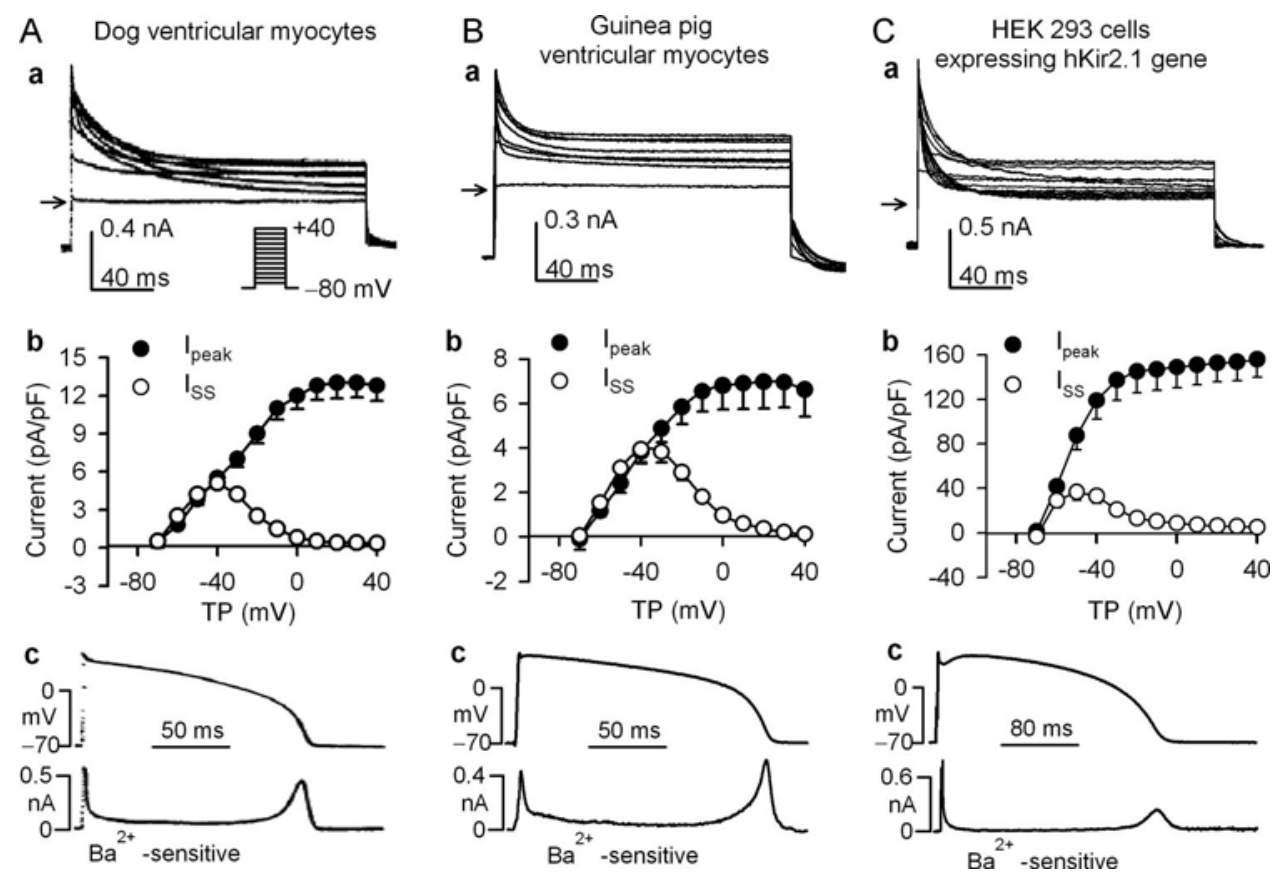

Fig. (1). $\mathrm{Ba}^{2+}$-sensitive transient outward component of cardiac $\mathrm{I}_{\mathbf{K} 1}$ channels activated by depolarization. $\mathbf{A}$-a. $\mathrm{Ba}^{2+}$-sensitive current was recorded in a dog ventricular myocyte, and obtained by digitally subtracting the currents before and after application of $200 \mu \mathrm{M} \mathrm{Ba}^{2+}$. Membrane currents were elicited with the voltage protocol shown in the inset. The arrow indicates the 0 current level. A-b. $I$ - $V$ relationships of the peak current ( $I_{\text {peak }}$, measured from current peak to 'quasi'-steady-sate level) showed intermediate inward rectification, while that of steady-state current ( $\mathrm{I}_{\mathrm{SS}}$, measured from holding current to the 'quasi'-steady-sate level) exhibited strong inward rectification (middle panel). A-c. Action potential (recorded from a dog ventricular myocyte) waveform clamp revealed two components of $\mathrm{Ba}^{2+}$ sensitive current. B-a. $\mathrm{Ba}^{2+}$-sensitive current recorded in a guinea pig ventricular myocytes with same protocol as shown in the inset of A-a. B-b. $I$ - $V$ relationships of $\mathrm{I}_{\text {peak }}$ and $\mathrm{I}_{\mathrm{SS}}$ showed similar properties to those in dog ventricular myocytes. A-c. Action potential (recorded from a guinea pig ventricular myocyte) waveform clamp also revealed two components of $\mathrm{Ba}^{2+}$ sensitive current. $\mathbf{C}$-a. $\mathrm{Ba}^{2+}$-sensitive current recorded in a $\mathrm{HEK} 293$ cell stably expressing human Kir2.1 gene with same protocol as shown in the inset of A-a. C-b. $I$ - $V$ relationships of $\mathrm{I}_{\text {peak }}$ and $\mathrm{I}_{\mathrm{SS}}$ in HEK Kir2.1 cell line showed similar properties to those in dog and guinea pig ventricular myocytes. C-c. Action potential (recorded from a human ventricular myocyte) waveform clamp also revealed two components of $\mathrm{Ba}^{2+}$ sensitive current in HEK cells stably expressing Kir2.1 gene. Modified from Li GR, et al, 1998; 2000; and Zhang DY, et al, 2009 [42, 59, 60].

currents; one was immediately elicited by the upstroke of action potential, and then rapidly inactivated during depolarization, another was slowly activated during repolarization of action potential (Fig. 1C-c), which are similar to those of $\mathrm{Ba}^{2+}-$ or $\mathrm{K}^{+}{ }_{0}$-sensitive current observed previously in native cardiac myocytes (Fig. 1A and 1B) [42, 59]. Interestingly, inactivation of the $I_{\text {to.ir }}$ was remarkably slowed by increasing free $\mathrm{Mg}^{2+}$ i (from 0.03 to $8.0 \mathrm{mM}$ ). The component elicited by upstroke of action potential increased with the elevation of $\mathrm{Mg}^{2+}$ i (Fig. 2C); however, inclusion of spermine $(100 \mu \mathrm{M})$ in the pipette solution inhibited both the $\mathrm{I}_{\text {to.ir }}$ and steady-state current of Kir2.1 channels. Spermine did not alter the property of inward rectification of human Kir2.1 current under physiological $\mathrm{K}^{+}{ }_{\mathrm{o}}$ (Fig. 3). Collectively, it should be confirmed that under physiological conditions $\mathrm{I}_{\mathrm{K} 1}$ channels or Kir2.1channels carry two components during cardiac action potential: one is transient outward elicited by upstroke, and another is steady-state activated by repolarization of action potential.

\section{PHYSIOLOGICAL ROLE OF I $I_{K 1}$ CHANNELS IN THE HEART}

It has been well recognized that cardiac $\mathrm{I}_{\mathrm{K} 1}$ or Kir2.x channels play a crucial role in maintaining resting membrane potential and excitability in the heart. The resting membrane potential is attributed to the inward rectification property of cardiac $\mathrm{I}_{\mathrm{K} 1}$ or Kir2.x channels, i.e. much more easily passing $\mathrm{K}^{+}$ions in the inward direction (into the cell) than in the outward direction (out of the cell). When membrane potential is negative to its resting potential $\left(E_{\mathrm{K}}\right)$, cardiac $\mathrm{I}_{\mathrm{K} 1}$ channels support the flow of positively charged $\mathrm{K}^{+}$ions into the cell, and repolarize the membrane potential back to the resting potential. On the other hand, when the membrane potential is positive to the resting potential, $\mathrm{I}_{\mathrm{K} 1}$ channels allow very little $\mathrm{K}^{+}$ions to pass out of the cell. Therefore, cardiac $\mathrm{I}_{\mathrm{K} 1}$ plays an important role in setting resting membrane potential level and also contributes to repolarization in the heart $[20,74]$. This is further demonstrated in guinea pig heart using gene transfer approach [75]. In this model, Miake and colleagues introduced adenoviruses with wild-type Kir2.1 or dominantnegative Kir2.1 gene into the left ventricular cavity of the animal and allowed the virus vectors to enter the coronary circulation and infiltrate ventricular tissue. They reported that overexpression of $\mathrm{I}_{\mathrm{K} 1}$ hyperpolarized, whereas suppression of $I_{K 1}$ depolarized the resting membrane potential. Greater $I_{K 1}$ currents shortened action potential duration, whereas suppression of $\mathrm{I}_{\mathrm{K} 1}$ increased action potential duration. In 

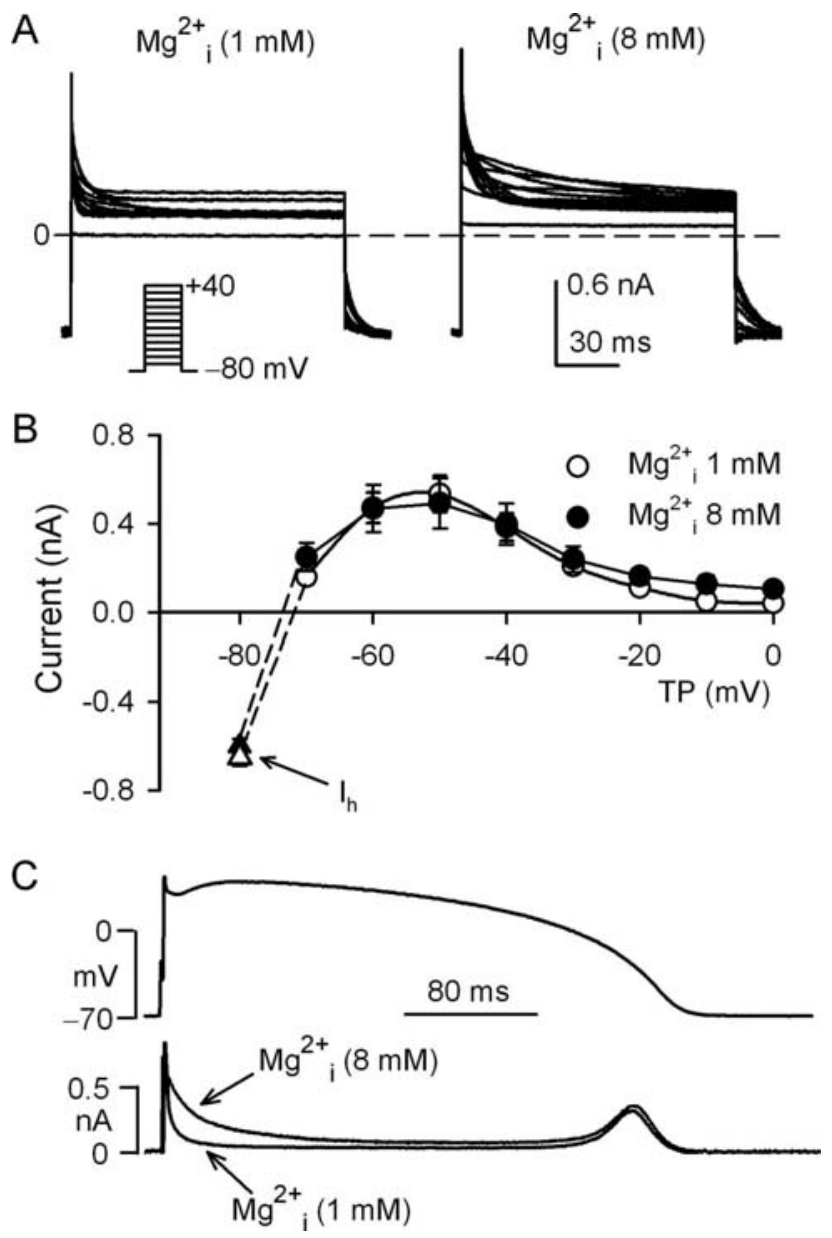

Fig. (2). Intracellular free $\mathrm{Mg}^{2+}$ and rectification of human Kir2.1 current. A. Kir2.1 current was activated by depolarization voltage steps (inset) in HEK 293 cells stably expressing Kir2.1 gene, in the presence of physiological free $\mathrm{Mg}^{2+}$ ( $1 \mathrm{mM}$, left panel) and $8 \mathrm{mM} \mathrm{Mg}^{2+}$ (right panel) in pipette solution. B. $I-V$ relationship of $\mathrm{I}_{\mathrm{SS}}$ (classic $\mathrm{I}_{\mathrm{K} 1}$ ) was not affected by increase of $\mathrm{Mg}^{2+}{ }_{\mathrm{i}}$. $\mathrm{I}_{\mathrm{h}}$, holding current. C. Action potential clamp reveals that elevation of $\mathrm{Mg}^{2+}{ }_{\mathrm{i}}$ induced an increased contribution of Kir2.1 channels to action potential during depolarization. Modified from Zhang DY, et al, 2009 [60].

addition, overexpression of $\mathrm{I}_{\mathrm{K} 1}$ resulted in a short QT interval, whereas suppression of $\mathrm{I}_{\mathrm{K} 1}$ caused a long QT phenotype [75].

Cell excitability has generally been associated with the ability of inward currents to generate an action potential upstroke. In addition to the contribution of $\mathrm{I}_{\mathrm{K} 1}$ channels in setting resting membrane potential to cardiac excitability [75], the depolarization-activated time- and voltagedependent component ( $\left.\mathrm{I}_{\mathrm{to} . \mathrm{ir}}\right)[42,59,60,68]$ of $\mathrm{I}_{\mathrm{K} 1}$ channels may control myocardial excitability. Because significant outward current carried by $\mathrm{I}_{\mathrm{K} 1}$ channels is elicited by depolarization of action potential at very negative potentials over a time course comparable to $\mathrm{I}_{\mathrm{Na}}$, which is distinct from the steady-state outward component of $\mathrm{I}_{\mathrm{K} 1}$ that shows as a later outward current during phase 3 repolarization of cardiac action potential. Therefore, $\mathrm{I}_{\text {to.ir }}$ of cardiac $\mathrm{I}_{\mathrm{K} 1}$ channels should make a significant contribution to $\mathrm{K}^{+}$efflux during phase 1 of action potential. The rapid recovery of the transient outward component of $\mathrm{I}_{\mathrm{K} 1}$ channels from inactivation suggests that its contribution to the action potential should be independent of the heart rate [42, 59, 60]. Thus, $I_{\text {to.ir }}$ of $I_{K 1}$ channels activated by upstroke of action potential should have physiological role in maintaining cardiac excitability, especially under pathophysiological conditions.

Inactivation of $\mathrm{I}_{\text {to.ir }}$ is strongly dependent on free $\mathrm{Mg}^{2+}{ }_{\mathrm{i}}$ [60]. Elevation of cytosolic free $\mathrm{Mg}^{2+}$ slows the inactivation of $\mathrm{I}_{\text {to.ir }}$ carried by human Kir2.1 channels, increases, but not reduces, the contribution of the current during depolarization of cardiac action potential, and therefore may reduce cellular excitability (Fig. 2). In native cardiac myocytes, the depolarization-activated $\mathrm{I}_{\text {to.ir }}$ contributes significantly to
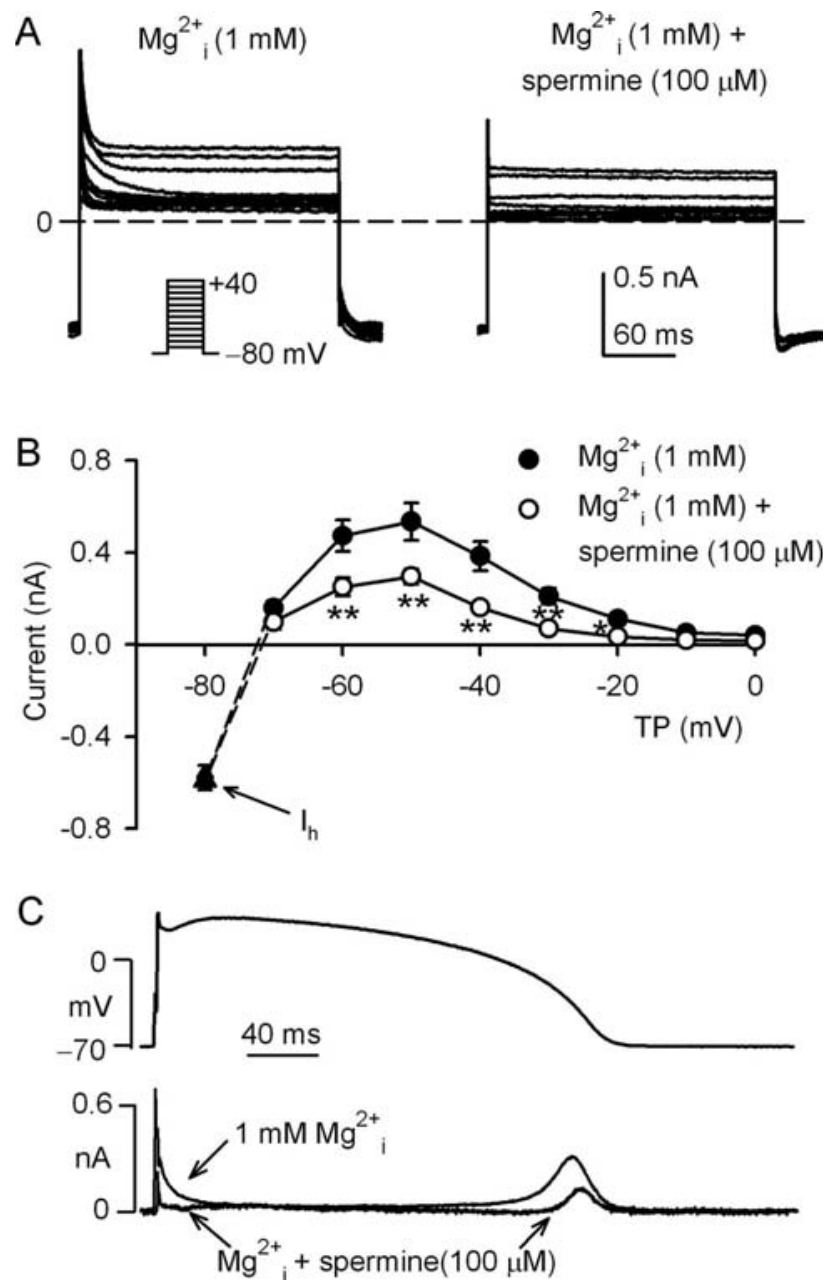

Fig. (3). Intracellular polyamines and rectification of human Kir2.1 current. A. Kir2.1 current was activated by depolarization voltage steps (inset) in HEK 293 cells stably expressing Kir2.1 gene, in the absence (left panel) or presence (right panel) of 100 $\mu \mathrm{M}$ spermine in pipette solution. B. $I-V$ relationship of $I_{S S}$ (classic $\mathrm{I}_{\mathrm{K} 1}$ ) showed an inhibition of outward component of Kir2.1 channels by spermine inclusion $\left({ }^{*} \mathrm{P}<0.05\right.$; $* * \mathrm{P}<0.01 \mathrm{vs} 1 \mathrm{mM} \mathrm{Mg}^{2+}{ }_{\mathrm{i}}$ ) without affecting the inward rectification. $\mathrm{I}_{\mathrm{h}}$, holding current. C. Action potential clamp revealed that inclusion of spermine in pipette solution abolishes the contribution of Kir2.1 channels to action potential during depolarization, and reduces contribution of the current to repolarization. Modified from Zhang DY, et al, 2009 [60]. 
phase 1 repolarization of action potential [42, 59] and therefore may play an important role in maintaining cardiac excitability. Earlier work by Murphy et al. demonstrated that cytosolic free $\mathrm{Mg}^{2+}$ level increased from $1 \mathrm{mM}$ to $>2.0 \mathrm{mM}$ during cardiac ischemia [76]. The increased cytosolic free $\mathrm{Mg}^{2+}$ level may actually reduce the excitability of ischemic myocardium.

On the other hand, additional inclusion of a high concentration of polyamines (spermine) in pipette solution strongly suppresses the $\mathrm{I}_{\text {to.ir }}$ component of Kir2.1 current and its steady-state component (classic component of $\mathrm{I}_{\mathrm{K} 1}$ ) under physiological $\mathrm{K}_{0}^{+}$, and therefore depolarization-activated component $\left(\mathrm{I}_{\text {to.ir }}\right)$ and repolarization-activated component of $\mathrm{I}_{\mathrm{K} 1}$ are reduced during the action potential (Fig. 3) [60]. Thus, cardiac excitability would be increased if intracellular free polyamines are elevated. Interestingly, total tissue concentrations of polyamines were significantly decreased during ischemia and reperfusion in rat hearts [77]. If a reduced intracellular concentration of free polyamines is combined with an increased free $\mathrm{Mg}^{2+}{ }_{i}$ during myocardial ischemia/reperfusion, the contribution of depolarizationactivated $\mathrm{I}_{\mathrm{to} \text {.ir }}$ and steady state component of $\mathrm{I}_{\mathrm{K} 1}$ channels would be increased during the action potential, which favors the maintenance of cardiac excitability.

\section{CONCLUSION}

With advances in patch clamp and gene cloning technologies, great progress has been made in the field of ion channel biology and particularly in $\mathrm{I}_{\mathrm{K} 1}$ study during the past decade. Inward rectifier $\mathrm{K}^{+}$channels have been cloned from many tissues, and their biophysical properties have been elucidated. Although the voltage-dependent block of $\mathrm{I}_{\mathrm{K} 1}$ channels by intracellular free polyamines and/or $\mathrm{Mg}^{2+}$ has been widely characterized to interpret the inward rectification, to that the effect was observed only under an increased $\mathrm{K}^{+}$o conditions, which remains to be re-evaluated under physiological $\mathrm{K}_{\mathrm{o}}^{+}$. More attention should be paid to the previously-ignored transient outward component of $\mathrm{I}_{\mathrm{K} 1}$ channels elicited by the upstroke of cardiac action potential in controlling cardiac excitability.

\section{ACKNOWLEDGEMENT}

This work was supported in part by a General Research Fund (HKU760306M) from Research Grant Council of Hong Kong. The authors thank Mr. Wentao Li for the critical reading of the manuscript.

\section{REFERENCES}

[1] Katz, B. Les constantes electriques de la membrane du muscle. Arch. Sci. Physiol, 1949, 2, 285.

[2] Weidmann, S. Rectifier properties of Purkinje fibers. Amer. J. Physiol., 1955, 183, 671.

[3] Mascher, D.; Peper, K. Two components of inward current in myocardial muscle fibers. Pflugers. Arch., 1969, 307(3), 190-203.

[4] Beeler, G.W.Jr.; Reuter, H. The relation between membrane potential, membrane currents and activation of contraction in ventricular myocardial fibres. J. Physiol., 1970, 207(1), 211-229.

[5] Rougier, O.; Vassort, G.; Stampfli, R. Voltage clamp experiments on frog atrial heart muscle fibres with the sucrose gap technique. Pflugers. Arch. Gesamte. Physiol. Menschen. Tiere., 1968, 301(2), 91-108.

[6] Hall, A.E.; Hutter, O.F.; Noble, D. Current-voltage relations of Purkinje fibres in sodium-deficient solutions. J. Physiol., 1963, $166,225-240$.
[7] Hutter, O.F.; Noble, D. Rectifying properties of heart muscle. Nature, 1960, 188, 495.

[8] Panama, B. K.; McLerie, M.; Lopatin, A. N. Heterogeneity of IK1 in the mouse heart. Am. J. Physiol. Heart. Circ. Physiol., 2007, 293(6), H3558-3567.

[9] Shah, A.K.; Cohen, I.S.; Datyner, N.B. Background K+ current in isolated canine cardiac Purkinje myocytes. Biophys. J., 1987, 52(4), 519-525.

[10] Koumi, S.; Backer, C.L.; Arentzen, C.E. Characterization of inwardly rectifying $\mathrm{K}^{+}$channel in human cardiac myocytes. Alterations in channel behavior in myocytes isolated from patients with idiopathic dilated cardiomyopathy. Circulation, 1995, 92(2), 164-174.

[11] Hirano, Y.; Hiraoka, M. Changes in $\mathrm{K}^{+}$currents induced by $\mathrm{Ba}^{2+}$ in guinea pig ventricular muscles. Am. J. Physiol., 1986, 25l(1 Pt 2), H24-33.

[12] Piao, L.; Li, J.; McLerie, M.; Lopatin, A.N. Cardiac $\mathrm{I}_{\mathrm{K} 1}$ underlies early action potential shortening during hypoxia in the mouse heart. J. Mol. Cell. Cardiol., 2007, 43(1), 27-38.

[13] Harvey, R.D.; Ten Eick, R.E. Characterization of the inwardrectifying potassium current in cat ventricular myocytes. J. Gen. Physiol., 1988, 91(4), 593-615.

[14] Biermans, G.; Vereecke, J.; Carmeliet, E. The mechanism of the inactivation of the inward-rectifying $\mathrm{K}$ current during hyperpolarizing steps in guinea-pig ventricular myocytes. Pflugers. Arch., 1987, 410(6), 604-613.

[15] Bailly, P.; Mouchoniere, M.; Benitah, J.P.; Camilleri, L.; Vassort, G.; Lorente, P. Extracellular $\mathrm{K}^{+}$dependence of inward rectification kinetics in human left ventricular cardiomyocytes. Circulation, 1998, 98(24), 2753-2759.

[16] Matsuda, H.; Saigusa, A.; Irisawa, H. Ohmic conductance through the inwardly rectifying $\mathrm{K}$ channel and blocking by internal $\mathrm{Mg} 2+$. Nature, 1987, 325(7000), 156-159.

[17] Mitra, R.L.; Morad, M. Permeance of $\mathrm{Cs}^{+}$and $\mathrm{Rb}^{+}$through the inwardly rectifying $\mathrm{K}^{+}$channel in guinea pig ventricular myocytes. J. Membr. Biol., 1991, 122(1), 33-42.

[18] Hamill, O.P.; Marty, A.; Neher, E.; Sakmann, B.; Sigworth, F.J. Improved patch-clamp techniques for high-resolution current recording from cells and cell-free membrane patches. Pflugers. Arch., 1981, 391(2), 85-100.

[19] Neher, E.; Sakmann, B. The patch clamp technique. Sci. Am., 1992 266(3), 44-51.

[20] Lopatin, A.N.; Nichols, C.G. Inward rectifiers in the heart: an update on I(K1). J. Mol. Cell. Cardiol., 2001, 33(4), 625-638.

[21] Dhamoon, A.S.; Jalife, J. The inward rectifier current $\left(\mathrm{I}_{\mathrm{K} 1}\right)$ controls cardiac excitability and is involved in arrhythmogenesis. Heart Rhythm, 2005, 2(3), 316-324.

[22] Lu, Z. Mechanism of rectification in inward-rectifier $\mathrm{K}^{+}$channels. Annu. Rev. Physiol., 2004, 66, 103-129.

[23] Kubo, Y.; Baldwin, T.J.; Jan, Y.N.; Jan, L.Y. Primary structure and functional expression of a mouse inward rectifier potassium channel. Nature, 1993, 362(6416), 127-133.

[24] Tang, W.; Yang, X.C. Cloning a novel human brain inward rectifier potassium channel and its functional expression in Xenopus oocytes. FEBS. Lett., 1994, 348(3), 239-243.

[25] Tempel, B.L.; Jan, Y.N.; Jan, L.Y. Cloning of a probable potassium channel gene from mouse brain. Nature, 1988, 332(6167), 837-839.

[26] Perier, F.; Coulter, K.L.; Radeke, C.M.; Vandenberg, C.A. Expression of an inwardly rectifying potassium channel in Xenopus oocytes. J. Neurochem., 1992, 59(5), 1971-1974.

[27] Perier, F.; Radeke, C.M.; Vandenberg, C.A. Primary structure and characterization of a small-conductance inwardly rectifying potassium channel from human hippocampus. Proc. Natl. Acad. Sci. USA, 1994, 91(13), 6240-6244.

[28] Raab-Graham, K.F.; Radeke, C.M.; Vandenberg, C.A. Molecular cloning and expression of a human heart inward rectifier potassium channel. Neuroreport, 1994, 5(18), 2501-2505.

[29] Snyders, D.J. Structure and function of cardiac potassium channels. Cardiovasc. Res., 1999, 42(2), 377-390.

[30] Yang, J.; Jan, Y.N.; Jan, L.Y. Determination of the subunit stoichiometry of an inwardly rectifying potassium channel. Neuron, 1995, 15(6), 1441-1447.

[31] Doyle, D.A.; Morais Cabral, J.; Pfuetzner, R.A.; Kuo, A.; Gulbis, J.M.; Cohen, S.L.; Chait, B.T. MacKinnon, R. The structure of the potassium channel: molecular basis of $\mathrm{K}^{+}$conduction and selectivity. Science, 1998, 280(5360), 69-77. 
[32] Tinker, A.; Jan, Y.N.; Jan, L.Y. Regions responsible for the assembly of inwardly rectifying potassium channels. Cell, 1996, 87(5), 857-868.

[33] Giles, W.R.; Imaizumi, Y. Comparison of potassium currents in rabbit atrial and ventricular cells. J. Physiol., 1988, 405(123-145.

[34] Preisig-Muller, R.; Schlichthorl, G.; Goerge, T.; Heinen, S.; Bruggemann, A.; Rajan, S.; Derst, C.; Veh, R.W. Daut, J. Heteromerization of Kir2.x potassium channels contributes to the phenotype of Andersen's syndrome. Proc. Natl. Acad. Sci. USA, 2002, 99(11), 7774-7779.

[35] Schram, G.; Pourrier, M.; Wang, Z.; White, M. Nattel, S. Barium block of Kir2 and human cardiac inward rectifier currents: evidence for subunit-heteromeric contribution to native currents. Cardiovasc. Res., 2003, 59(2), 328-338.

[36] Tamargo, J.; Caballero, R.; Gomez, R.; Valenzuela, C.; Delpon, E. Pharmacology of cardiac potassium channels. Cardiovasc. Res., 2004, 62(1), 9-33.

[37] Zobel, C.; Cho, H.C.; Nguyen, T.T.; Pekhletski, R.; Diaz, R.J.; Wilson, G.J.; Backx, P.H. Molecular dissection of the inward rectifier potassium current $\left(\mathrm{I}_{\mathrm{K} 1}\right)$ in rabbit cardiomyocytes: evidence for heteromeric co-assembly of Kir2.1 and Kir2.2. J. Physiol., 2003, 550(Pt 2), 365-372.

[38] Dhamoon, A.S.; Pandit, S.V.; Sarmast, F.; Parisian, K.R.; Guha, P.; Li, Y.; Bagwe, S.; Taffet, S.M.; Anumonwo, J.M. Unique Kir2.x properties determine regional and species differences in the cardiac inward rectifier K ${ }^{+}$current. Circ. Res., 2004, 94(10), 1332-1339.

[39] Jongsma, H.J.; Wilders, R. Channelopathies: Kir2.1 mutations jeopardize many cell functions. Curr. Biol., 2001, 11(18), R747750 .

[40] Melnyk, P.; Zhang, L.; Shrier, A. Nattel, S. Differential distribution of Kir2.1 and Kir2.3 subunits in canine atrium and ventricle. Am. J. Physiol. Hear. Circ. Physiol., 2002, 283(3), H1123-1133.

[41] Amos, G.J.; Wettwer, E.; Metzger, F.; Li, Q.; Himmel, H.M.; Ravens, U. Differences between outward currents of human atrial and subepicardial ventricular myocytes. J. Physiol., 1996, 491(Pt 1), 31-50.

[42] Li, G.R.; Yang, B.; Sun, H. Baumgarten, C.M. Existence of a transient outward $\mathrm{K}(+)$ current in guinea pig cardiac myocytes. Am. J. Physiol. Heart Circ. Physiol., 2000, 279(1), H130-138.

[43] Bosch, R.F.; Zeng, X.; Grammer, J.B.; Popovic, K.; Mewis, C.; Kuhlkamp, V. Ionic mechanisms of electrical remodeling in human atrial fibrillation. Cardiovasc. Res., 1999, 44(1), 121-131.

[44] Li, G.R.; Lau, C.P.; Leung, T.K.; Nattel, S. Ionic current abnormalities associated with prolonged action potentials in cardiomyocytes from diseased human right ventricles. Heart Rhythm, 2004, 1(4), 460-468.

[45] Wang, Z.; Yue, L.; White, M.; Pelletier, G.; Nattel, S. Differential distribution of inward rectifier potassium channel transcripts in human atrium versus ventricle. Circulation, 1998, 98(22), 24222428.

[46] Yan, D.H.; Nishimura, K.; Yoshida, K.; Nakahira, K.; Ehara, T.; Igarashi, K.; Ishihara, K. Different intracellular polyamine concentrations underlie the difference in the inward rectifier $\mathrm{K}(+)$ currents in atria and ventricles of the guinea-pig heart. J. Physiol., 2005, 563(Pt 3), 713-724.

[47] Vandenberg, C.A. Inward rectification of a potassium channel in cardiac ventricular cells depends on internal magnesium ions. Proc. Natl. Acad. Sci. USA, 1987, 84(8), 2560-2564.

[48] Kurachi, Y. Voltage-dependent activation of the inward-rectifier potassium channel in the ventricular cell membrane of guinea-pig heart. J. Physiol., 1985, 366, 365-385.

[49] Ishihara, K.; Mitsuiye, T.; Noma, A.; Takano, M. The $\mathrm{Mg}^{2+}$ block and intrinsic gating underlying inward rectification of the $\mathrm{K}+$ current in guinea-pig cardiac myocytes. J. Physiol., 1989, 419, 297320 .

[50] Silver, M.R.; DeCoursey, T.E. Intrinsic gating of inward rectifier in bovine pulmonary artery endothelial cells in the presence or absence of internal $\mathrm{Mg}^{2+}$. J. Gen. Physiol., 1990, 96(1), 109-133.

[51] Stanfield, P.R.; Davies, N.W.; Shelton, P.A.; Khan, I.A.; Brammar, W.J.; Standen, N.B.; Conley, E.C. The intrinsic gating of inward rectifier $\mathrm{K}+$ channels expressed from the murine IRK1 gene depends on voltage, $\mathrm{K}^{+}$and $\mathrm{Mg}^{2+}$. J. Physiol., 1994, 475(1), 1-7.

[52] Lopatin, A.N.; Makhina, E.N.; Nichols, C.G. Potassium channel block by cytoplasmic polyamines as the mechanism of intrinsic rectification. Nature, 1994, 372(6504), 366-369.
[53] Ficker, E.; Taglialatela, M.; Wible, B.A.; Henley, C.M.; Brown, A.M. Spermine and spermidine as gating molecules for inward rectifier K ${ }^{+}$channels. Science, 1994, 266(5187), 1068-1072.

[54] Stanfield, P.R.; Nakajima, S.; Nakajima, Y. Constitutively active and G-protein coupled inward rectifier $\mathrm{K}^{+}$channels: Kir2.0 and Kir3.0. Rev. Physiol. Biochem. Pharmacol., 2002, 145, 47-179.

[55] Xie, L.H.; John, S.A.; Weiss, J.N. Inward rectification by polyamines in mouse Kir2.1 channels: synergy between blocking components. J. Physiol., 2003, 550(Pt 1), 67-82.

[56] Xie, L.H.; John, S.A.; Weiss, J.N. Spermine block of the strong inward rectifier potassium channel Kir2.1: dual roles of surface charge screening and pore block. J. Gen. Physiol., 2002, 120(1), 53-66.

[57] Yamada, M.; Kurachi, Y. Spermine gates inward-rectifying muscarinic but not ATP-sensitive $\mathrm{K}^{+}$channels in rabbit atrial myocytes. Intracellular substance-mediated mechanism of inward rectification. J. Biol. Chem., 1995, 270(16), 9289-9294.

[58] Ishihara, K.; Ehara, T. A repolarization-induced transient increase in the outward current of the inward rectifier $\mathrm{K}^{+}$channel in guineapig cardiac myocytes. J. Physiol., 1998, 510 (Pt 3), 755-771.

[59] Li, G.R.; Sun, H.; Nattel, S. Characterization of a transient outward $\mathrm{K}^{+}$current with inward rectification in canine ventricular myocytes. Am. J. Physiol. Cell. Physiol., 1998, 274(3 Pt 1), C577-585.

[60] Zhang, D.Y.; Lau, C.P.; Li, G.R. Human Kir2.1 channel carries a transient outward potassium current with inward rectification. Pflugers. Arch., 2009, 457(6), 1275-1285.

[61] Martin, R.L.; Koumi, S.; Ten Eick, R.E. Comparison of the effects of internal $\left[\mathrm{Mg}^{2+}\right]$ on $\mathrm{I}_{\mathrm{K} 1}$ in cat and guinea-pig cardiac ventricular myocytes. J. Mol. Cell. Cardiol., 1995, 27(1), 673-691.

[62] Ishihara, K.; Ehara, T. Two modes of polyamine block regulating the cardiac inward rectifier $\mathrm{K}^{+}$current $\mathrm{I}_{\mathrm{K} 1}$ as revealed by a study of the Kir2.1 channel expressed in a human cell line. J. Physiol., 2004, 556(Pt 1), 61-78.

[63] Coburn, R.F. Polyamine effects on cell function: Possible central role of plasma membrane PI(4,5)P2. J. Cell. Physiol., 2009, 221(3), 544-551.

[64] Ray, R.M.; Zimmerman, B.J.; McCormack, S.A.; Patel, T.B.; Johnson, L.R. Polyamine depletion arrests cell cycle and induces inhibitors p21(Waf1/Cip1), p27(Kip1), and p53 in IEC-6 cells. Am. J. Physiol. Cell. Physiol., 1999, 276(3 Pt 1), C684-691.

[65] Xiao, L.; Rao, J.N.; Zou, T.; Liu, L.; Marasa, B.S.; Chen, J.; Turner, D.J.; Zhou, H.; Gorospe, M.; Wang, J.Y. Polyamines regulate the stability of activating transcription factor- 2 mRNA through RNA-binding protein HuR in intestinal epithelial cells. Mol. Biol. Cell., 2007, 18(11), 4579-4590.

[66] Martin, R.L.; Barrington, P.L.; Ten Eick, R.E. A 3,4diaminopyridine-insensitive, $\mathrm{Ca}(2+)$-independent transient outward $\mathrm{K}^{+}$current in cardiac ventricular myocytes. Am. J. Physiol., 1994, 266(4 Pt 2), H1286-1299.

[67] Li, J.; McLerie, M.; Lopatin, A.N. Transgenic upregulation of $\mathrm{I}_{\mathrm{K} 1}$ in the mouse heart leads to multiple abnormalities of cardiac excitability. Am. J. Physiol. Heart. Circ. Physiol., 2004, 287(6), H2790-2802.

[68] Zhabyeyev, P.; Asai, T.; Missan, S.; McDonald, T.F. Transient outward current carried by inwardly rectifying $\mathrm{K}^{+}$channels in guinea pig ventricular myocytes dialyzed with low- $\mathrm{K}^{+}$solution. Am. J. Physiol. Cell. Physiol., 2004, 287(5), C1396-1403.

[69] Noble, D. The surprising heart: a review of recent progress in cardiac electrophysiology. J. Physiol., 1984, 353, 1-50.

[70] Nichols, C.G.; Makhina, E.N.; Pearson, W.L.; Sha, Q.; Lopatin, A.N. Inward rectification and implications for cardiac excitability. Circ. Res., 1996, 78(1), 1-7.

[71] Matsuoka, S.; Sarai, N.; Kuratomi, S.; Ono, K.; Noma, A. Role of individual ionic current systems in ventricular cells hypothesized by a model study. Jpn. J. Physiol., 2003, 53(2), 105-123.

[72] Shimoni, Y.; Clark, R.B.; Giles, W.R. Role of an inwardly rectifying potassium current in rabbit ventricular action potential. $J$. Physiol., 1992, 448, 709-727.

[73] Saigusa, A.; Matsuda, H. Outward currents through the inwardly rectifying potassium channel of guinea-pig ventricular cells. Jpn. J. Physiol., 1988, 38(1), 77-91.

[74] Ehrlich, J.R. Inward rectifier potassium currents as a target for atrial fibrillation therapy. J. Cardiovasc. Pharmacol., 2008, 52(2), 129-135.

[75] Miake, J.; Marban, E.; Nuss, H.B. Functional role of inward rectifier current in heart probed by Kir2.1 overexpression and 
dominant-negative suppression. J. Clin. Invest., 2003, 111(10), 1529-1536.

[76] Murphy, E.; Steenbergen, C.; Levy, L.A.; Raju, B.; London, R.E. Cytosolic free magnesium levels in ischemic rat heart. J. Biol. Chem., 1989, 264(10), 5622-5627.
[77] Han, L.; Xu, C.; Guo, Y.; Li, H.; Jiang, C.; Zhao, Y. Polyamine metabolism in rat myocardial ischemia-reperfusion injury. Int. J. Cardiol., 2009, 132(1), 142-144.

Received: January 12, 2010

Revised: February 28, 2010

Accepted: March 01, 2010

(C) Li and Dong; Licensee Bentham Open.

This is an open access article licensed under the terms of the Creative Commons Attribution Non-Commercial License (http://creativecommons.org/licenses/by-nc/3.0/) which permits unrestricted, non-commercial use, distribution and reproduction in any medium, provided the work is properly cited. 